\title{
Analysis of fatigue and damage in glass-fibre-reinforced polypropylene composite materials
}

\author{
J.A.M. Ferreira ${ }^{\mathrm{a}, *}$, J.D.M. Costa ${ }^{\mathrm{a}}$, P.N.B. Reis ${ }^{\mathrm{b}}$, M.O.W. Richardson ${ }^{\mathrm{c}}$ \\ ${ }^{a}$ Department of Mechanical Engineering, FCT/UC, University of Coimbra, Pinhal de Marrocos, 3030 Coimbra, Portugal \\ ${ }^{\mathrm{b}}$ Department of Electromechanical Engineering, UBI, 6200 Covilhã, Portugal \\ ${ }^{\mathrm{C}} I P T M E$, Loughborough University, Loughborough LE11 3TU, UK
}

Received 13 May 1998; received in revised form 16 October 1998; accepted 5 November 1998

\begin{abstract}
This paper concerns fatigue studies of polypropylene/glass-fibre thermoplastic composites produced from a bi-directional woven cloth of co-mingled E-glass fibres and polypropylene fibres with a fibre volume fraction $V_{f}$ of 0.338 . The effect of lay-up design and load conditions on fatigue performance were investigated. The S-N curves, the rise in the temperature of the specimens, and the loss of stiffness during the tests, are discussed. Fatigue tests were performed in controlled displacement mode and in an imposed stress range. Similar results were obtained for both load conditions. The loss of stiffness was used as a damage parameter and related to the rise of temperature. The results show that the damage parameter $E$ present a nearly linear relationship with the rise in temperature. A small deviation was probably caused by the stress release observed in the first period of fatigue life. (C) 1999 Elsevier Science Ltd. All rights reserved.
\end{abstract}

Keywords: A. Glass fibres; A. Polymer-matrix composites; B. Fatigue; B. Strength; C. Damage mechanics

\section{Introduction}

Thermoplastic resins with high average molecular weight and high crystallinity exhibit relatively high melting temperatures and mechanical properties. Advanced fibre-reinforced thermoplastic composites fabrics, which consist of thermoplastic filaments interwoven with reinforcing E-glass fibres have been developed recently which enable thermoplastic composites to be produced and are today good alternatives to thermosetting resin systems. The most attractive features offered by thermoplastic composites are the potential of low-cost manufacturing, high fracture toughness, good damage tolerance and impact resistance, good resistance to microcracking, easy quality control and the possibility to recycle the raw materials. A variety of thermoplastic resins have been investigated as matrices, including polypropylene, Nylon, polyetherimide, poly (phenylene sulphide) poly(ether ether ketone), etc. Meng Hou et al. [1] have reviewed the relative costs of different material forms and the manufacturing techniques required.

\footnotetext{
* Corresponding author. Fax: +351-39-790701; e-mail: martins.
} ferreira@mail.dem.uc.pt
The most important thermoplastic applications are in the automobile industry including panels, seat frames, bumper beams, load floors, front-end structures, head lamp retainers, rocker panels, under-engine covers, etc. [2] Other long fiber thermoplastic applications are reported in the construction, electrical and recreational sectors. One of the most important applications of glass reinforced polypropylene is in automotive body panels made by low cost thermoforming techniques.

This paper presents results associated with a glassfibre-reinforced polypropylene composite where the influence of the fibre orientation and load mode on fatigue behaviour were investigated. The fatigue strength was obtained in terms of the number of cycles to failure versus the stress range. In previous work of the authors $[3,4]$ other parameters such as frequency and stress concentration were reported.

The main objective of this work was to understand the damage mechanisms observed during the fatigue process. One of the fatigue damage parameter reported in the literature [5-7] is the rise in specimen temperature which increases with fatigue life especially close to final failure. The specific rise in temperature was measured for all the tests using a thermocouple method with three probes placed in the failure region. 
Other fatigue damage investigated included the residual stress, the loss of stiffness, the events number detected by ultrasonic analysis and fracture mechanics parameters. Wen-Fang Wu et al. [8] selected the residual stiffness as a parameter to describe the degradation behaviour and to predict the fatigue life in graphite/ epoxy composite laminates. Spearing and Beaumont [9] analysed the residual stress and the split length obtained by radiographic techniques in carbon epoxy laminates. The loss of stiffness during fatigue tests has been investigated as a damage criteria by Hahn and Kim [10] and Joseph and Perreux [11] in glass/epoxy, the authors [3,4] in glass/polypropylene and Echtermeyer et al. [12] in glass/phenolic and glass/polyester composites. Czigany and Karger-Kocsis [13] quantified fatigue damage by the size of the damage zones in textile fabric reinforced polypropylene composites using the acoustic emission technique. Wysgoski and Novak [14] analysed the fatigue damage of Nylon 66 reinforced by chopped, short fiber and long fibers of glass, carbon and aramid using conventional fracture mechanics curves of $\mathrm{d} a / \mathrm{d} N$ versus $\Delta K$.

The lay-up geometry has a strong influence on fatigue strength. This effect was investigated by Curtis [15], Harris et al. [16] and Rotem and Nelson [17] in carbon/ epoxy composites.

The objectives of the current study were to investigate the effect of lay-up geometry on the fatigue strength and fatigue damage of polypropylene resins reinforced by bi-directional E-glass fibre layers.

\section{Material and experimental procedures}

Composite sheets were formed from multi-layers of Vetrotex "Twintex T PP" which were processed in a mould under pressure ( 5 bar for ten min) after heating at $190^{\circ} \mathrm{C}$. This temperature was chosen to be above the melting temperature of the polypropylene. Each sheet were made up of seven woven balanced bi-directional ply layers. The overall dimensions of the plates were $160 \mathrm{~mm} \times 250 \mathrm{~mm} \times 3 \mathrm{~mm}$ with a fibre volume fraction of 0.338 . Quality control of the plates include visual inspection of the colour and void content.

Three types of plate were manufactured. For one series of plates all the layers plies have one of the two fibre directions orientated with the axis of the plate. The other two plates had the following ply orientation with respect to the axis of the sheet: $+45^{\circ} / 0^{\circ} /-45^{\circ} / 0^{\circ} /+45^{\circ} /$ $0^{\circ} /-45^{\circ}$ and $+30^{\circ} /-30^{\circ} /+30^{\circ} / 0^{\circ} /+30^{\circ} /-30^{\circ} /+30^{\circ}$. For convenience these three types are referred as $0^{\circ}$, $+45^{\circ} / 0^{\circ} /-45^{\circ}$ and $+30^{\circ} /-30^{\circ} / 0^{\circ}$, plates respectively.

The specimens used in the fatigue tests were prepared from these thin plates. The geometry and dimensions of the fatigue specimens are shown in Fig. 1. Two types of test were performed. One series of fatigue tests were

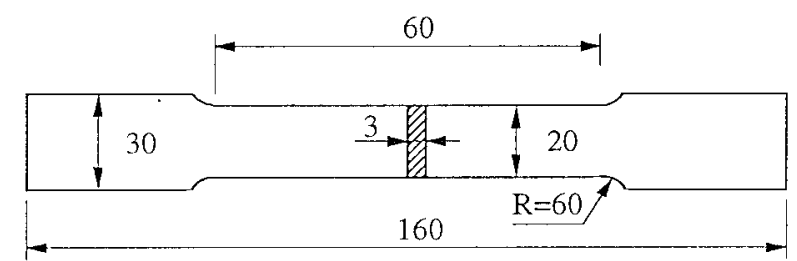

Fig. 1. Fatigue test specimen (dimensions in $\mathrm{mm}$ ).

carried out in an electromechanical machine where frequency and stress ratio can be changed and the load is controlled by a load cell. The tests were performed in constant amplitude displacement mode (the load wave was sinusoidal constant amplitude). Other series of tests were carried out in an servo-hydraulic Instron machine in constant amplitude load. All the tests were performed in tension with stress ratio $R=0.025$ and frequency $10 \mathrm{~Hz}$ at ambient temperature.

The displacement in constant amplitude displacement mode was imposed by the eccentricity of one piston rod and crank system and measured using a dynamic axial extensometer fixed in the specimen.

During the fatigue tests the temperature rise at three points on the surface of the specimens was measured using thermocouples and recorded in a computer. Periodically the procedures were stopped and a static loading test carried out. The stiffness modulus was derived from the stress-strain curves obtained. These curves where nearly linear in the low stress level. The stiffness modulus was calculated by linear regression of the curves in the nearly linear region.

The tensile mechanical properties were obtained using an electromechanical Instron Universal Testing machine. Table 1 presents the results obtained with a grip displacement rate of $2000 \mathrm{~mm} / \mathrm{min}$. This test rate was chosen to be similar to the mean fatigue test deformation rate. The tabled values are the average of four tests carried out for each test condition. These results show that the $0^{\circ}$ laminate exhibits an higher strength and stiffness than the $+45^{\circ} / 0^{\circ} /-45^{\circ}$ and $+30^{\circ} /-30^{\circ} / 0^{\circ}$ laminates as was expected. The failure mechanisms in each case were quite different. In the $0^{\circ}$ laminate the failure was dominated by the fracture of axially aligned fibers and in $+45^{\circ} / 0^{\circ} /-45^{\circ}$ and $+30^{\circ} /-30^{\circ} / 0^{\circ}$ laminates delamination of inclinated fibers layers was predominant. The two different fracture modes exhibited during static testing are shown in Fig. 2.

Table 1

Mechanical properties (strain loading $0.333 \mathrm{~s}^{-1}$ )

\begin{tabular}{lll}
\hline Laminate & $\begin{array}{l}\text { Ultimate strength } \\
\left(\sigma_{\mathrm{UTS}}\right)(\mathrm{MPa})\end{array}$ & $\begin{array}{l}\text { Stiffness coefficient } \\
(E)(\mathrm{MPa})\end{array}$ \\
\hline 0 & 438 & 15,916 \\
$+30^{\circ} /-30^{\circ} / 0^{\circ}$ & 211 & 9,113 \\
$+45^{\circ} / 0^{\circ} /-45^{\circ}$ & 196 & 10,138 \\
\hline
\end{tabular}




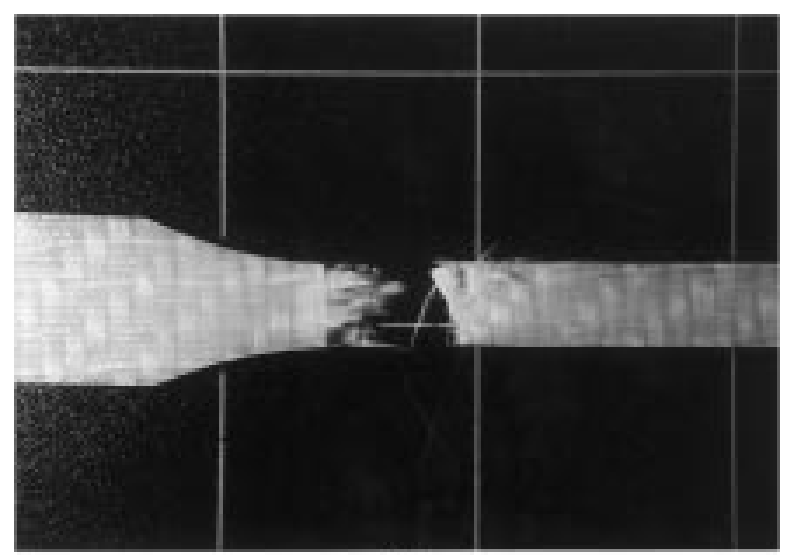

(a)

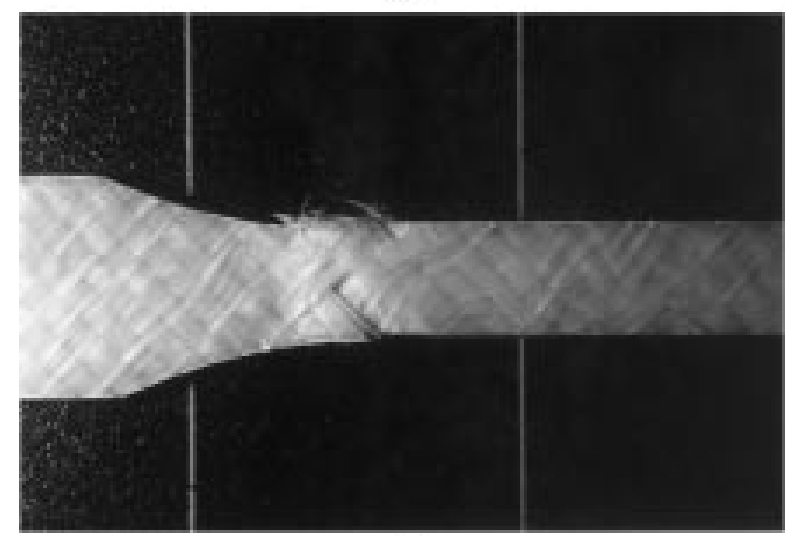

(b)

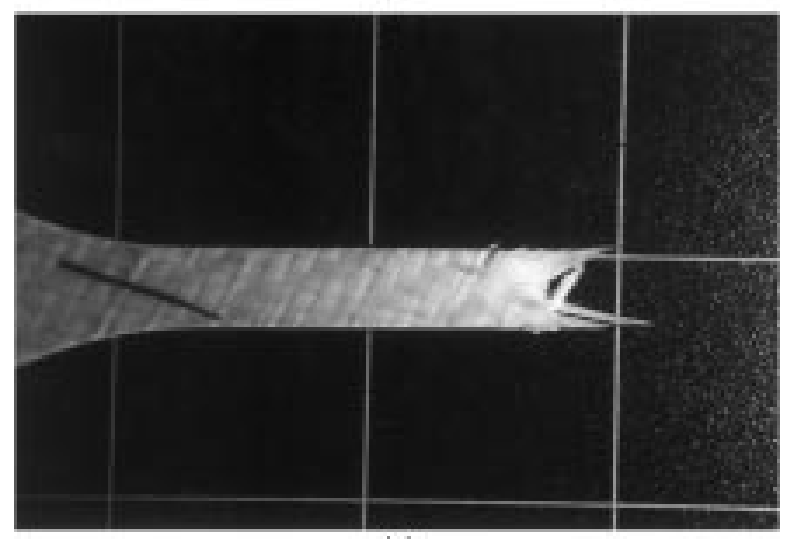

(c)

Fig. 2. Static test fracture specimens. (a) $0^{\circ}$; (b) $+45^{\circ} / 0^{\circ} /-45^{\circ}$; (c) $+30^{\circ} /-30^{\circ} / 0^{\circ}$.

\section{Results and discussion}

The three types of laminates $\left(0^{\circ},+45^{\circ} / 0^{\circ} /-45^{\circ}\right.$ and $+30^{\circ} /-30^{\circ} / 0^{\circ}$ ) were tested in load amplitude control and displacement amplitude control. During all the fatigue tests the temperature rise at three points on the surface of the specimens were measured and periodically the static stiffness modulus was obtained (as described earlier). These parameters are used in this discussion to interpret and understand the damage mechanisms. In
Table 2

Fatigue tests parameters

\begin{tabular}{|c|c|c|c|}
\hline Tests number & $\begin{array}{l}\text { Control } \\
\text { mode }\end{array}$ & $\begin{array}{l}\text { Stress range } \\
(\mathrm{MPa})\end{array}$ & $\begin{array}{l}\text { Number of } \\
\text { cycles to } \\
\text { failure }\end{array}$ \\
\hline FT0-1 & Stress & 150 & 49,252 \\
\hline FT0-2 & Stress & 150 & 43,053 \\
\hline FT0-3 & Stress & 140 & 67,747 \\
\hline FT0-4 & Stress & 164 & 21,254 \\
\hline FT0-5 & Stress & 164 & 40,268 \\
\hline FT0-6 & Stress & 145 & 101,421 \\
\hline FT0-7 & Stress & 140 & 386,054 \\
\hline FT0-8 & Stress & 130 & 212,957 \\
\hline FT0-9 & Stress & 130 & $1,062,232$ \\
\hline FT45-1 & Stress & 85 & $1,654,000$ \\
\hline FT45-2 & Stress & 90 & $1,233,726$ \\
\hline FT45-3 & Stress & 95 & 754,506 \\
\hline FT45-4 & Stress & 95 & 123,547 \\
\hline FT45-5 & Stress & 100 & 240,243 \\
\hline FT45-6 & Stress & 100 & 205,878 \\
\hline FT45-7 & Stress & 105 & 36,943 \\
\hline FT45-8 & Stress & 105 & 65,573 \\
\hline FT45-9 & Stress & 110 & 17,413 \\
\hline FT30-1 & Stress & 80 & 474,979 \\
\hline FT30-2 & Stress & 85 & 587,348 \\
\hline FT30-3 & Stress & 85 & 117,579 \\
\hline FT30-4 & Stress & 85 & 111,098 \\
\hline FT30-5 & Stress & 90 & 32,889 \\
\hline FT30-6 & Stress & 95 & 101,708 \\
\hline FT30-7 & Stress & 95 & 23,314 \\
\hline FT30-8 & Stress & 100 & 20,931 \\
\hline FT30-9 & Stress & 110 & 10,250 \\
\hline FD0-1 & Displacement & 120.3 & 540,300 \\
\hline FD0-2 & Displacement & 109.3 & $1,443,500$ \\
\hline FD0-3 & Displacement & 106.2 & $1,631,400$ \\
\hline FD0-4 & Displacement & 141.5 & 375,810 \\
\hline FD0-5 & Displacement & 128.7 & 536,100 \\
\hline FD0-6 & Displacement & 181.6 & 4,060 \\
\hline FD0-7 & Displacement & 175 & 20,900 \\
\hline FD0-8 & Displacement & 139 & 381,270 \\
\hline FD0-9 & Displacement & 153 & 95,201 \\
\hline FD0-10 & Displacement & 121 & 466,500 \\
\hline FD0-11 & Displacement & 111 & $1,755,200$ \\
\hline FD0-12 & Displacement & 147 & 428,380 \\
\hline FD0-13 & Displacement & 167 & 40,211 \\
\hline FD0-14 & Displacement & 176 & 37,942 \\
\hline FD0-15 & Displacement & 120 & 488,250 \\
\hline FD45-1 & Displacement & 108.8 & 57,683 \\
\hline FD45-2 & Displacement & 83.6 & $2,050,000$ \\
\hline FD45-3 & Displacement & 80.4 & $1,850,000$ \\
\hline FD45-4 & Displacement & 97.4 & 72,334 \\
\hline FD45-5 & Displacement & 95.6 & 212,040 \\
\hline FD45-6 & Displacement & 91.6 & 205,360 \\
\hline FD45-7 & Displacement & 104.2 & 51,450 \\
\hline FD45-8 & Displacement & 110 & 4,411 \\
\hline FD45-9 & Displacement & 120.1 & 4,839 \\
\hline FD30-1 & Displacement & 109.1 & 13,350 \\
\hline FD30-2 & Displacement & 85.4 & 170,000 \\
\hline FD30-3 & Displacement & 97.6 & 57,000 \\
\hline FD30-4 & Displacement & 93.5 & 327,840 \\
\hline FD30-5 & Displacement & 70 & $3,406,000$ \\
\hline FD30-6 & Displacement & 81.5 & 650,000 \\
\hline FD30-7 & Displacement & 81.1 & 360,300 \\
\hline FD30-8 & Displacement & 72.7 & $2,071,000$ \\
\hline
\end{tabular}


Table 2 it is summarised the test conditions and the number of cycles to failure of the fatigue tests.

For analysis purposes the highest of the three recorded surface temperatures was used in each case. Figs. 3(a) and (b) show the increase in temperature versus the dimensionless life $N / N_{\mathrm{f}}$ (where $N$ is the number of cycles at any given instant of the test, $N_{\mathrm{f}}$ is the number of cycles to failure) for $0^{\circ}$ and $+30^{\circ} /-30^{\circ} / 0^{\circ}$ laminate, respectively. Similar results were obtained for $+45^{\circ} / 0^{\circ} /-45^{\circ}$ laminates. The rise of temperature associated with both load amplitude and displacement control tests were plotted. These figures show similar behaviour for both types of laminate. The maximum temperature in both laminates occurred at failure. Generally speaking there is an inverse relationship between temperature and stiffness (Fig. 4). It can be seen that there is an initial increase of temperature followed by a stage where it is nearly stabilised followed thereafter by a very small increase until close to failure. At this point a sudden increase of temperature occurs followed by failure of the specimen. During the second stage there is a balance between the rate of deformation energy lost
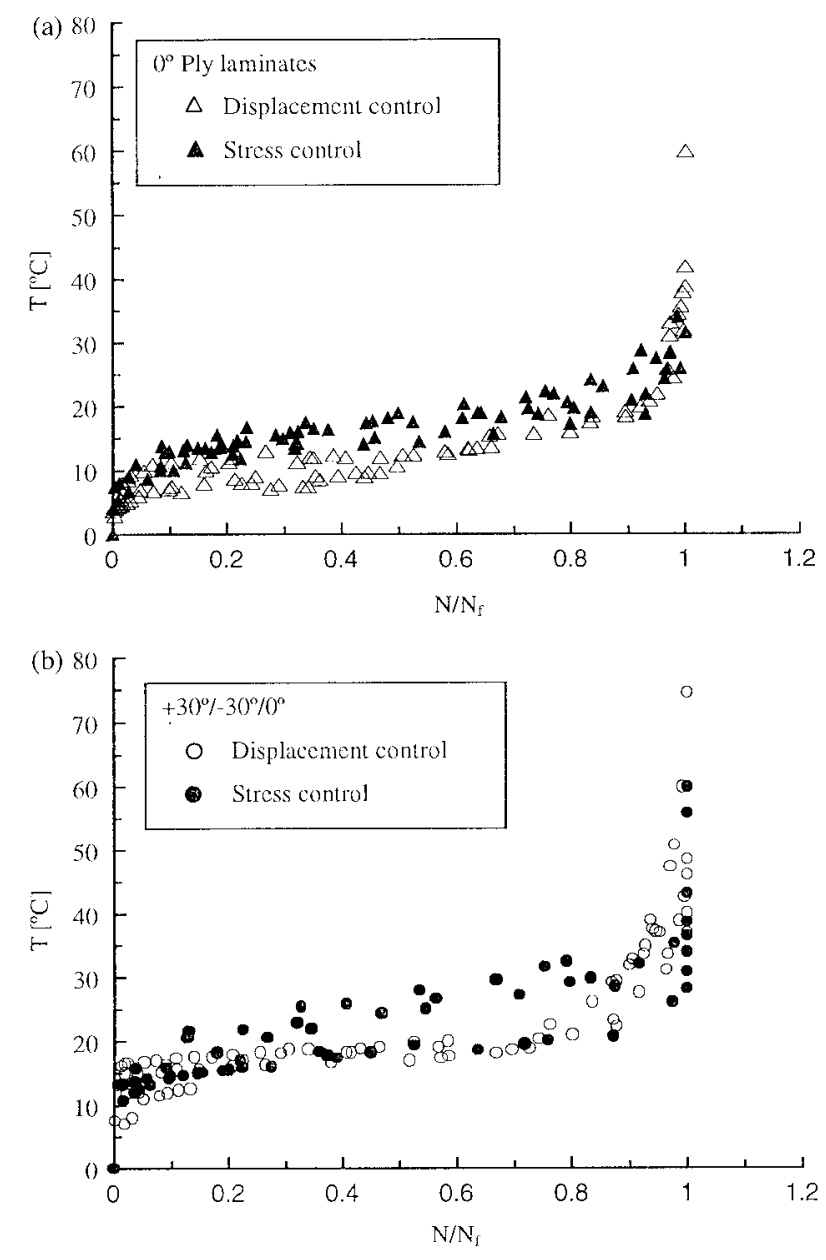

Fig. 3. Rises in surface temperature. (a) $0^{\circ}$; (b) $+30^{\circ} /-30^{\circ} / 0^{\circ}$. by the material and the energy dissipation rate. In the third period the rate of energy release caused by failure of the matrix and fibers is predominantly high and the temperature increases quickly. The rise in temperature is dependent of the load stress range especially close to failure that was (in the range $25-75^{\circ} \mathrm{C}$ ). However, no correlation is evident between the rise in temperature and the stress range. Similar behaviour occurs for both test loading modes (stress range or strain range control) despite a tendency to reach higher temperature values in the first case (stress range mode).

Fig. 4(a) and (b) plots $E / E_{0}$ versus $N / N_{\mathrm{f}}$ for $0^{\circ}$ and $+30^{\circ} /-30^{\circ} / 0^{\circ}$ laminates, respectively, where $E$ is stiffness modulus at any given moment of the test and $E_{0}$ is the stiffness modulus at the start. These figures show that similar behaviour occurs in the two laminates namely a significant drop in stiffness modulus during the first fatigue cycles (an average drop about of $5 \%$ during the first $5 \%$ of the fatigue life). Thereafter, the stiffness modulus decreases slowly until close to final failure. During the last $5 \%$ of fatigue life the stiffness modulus drops suddenly. During the first $20 \%$ of the
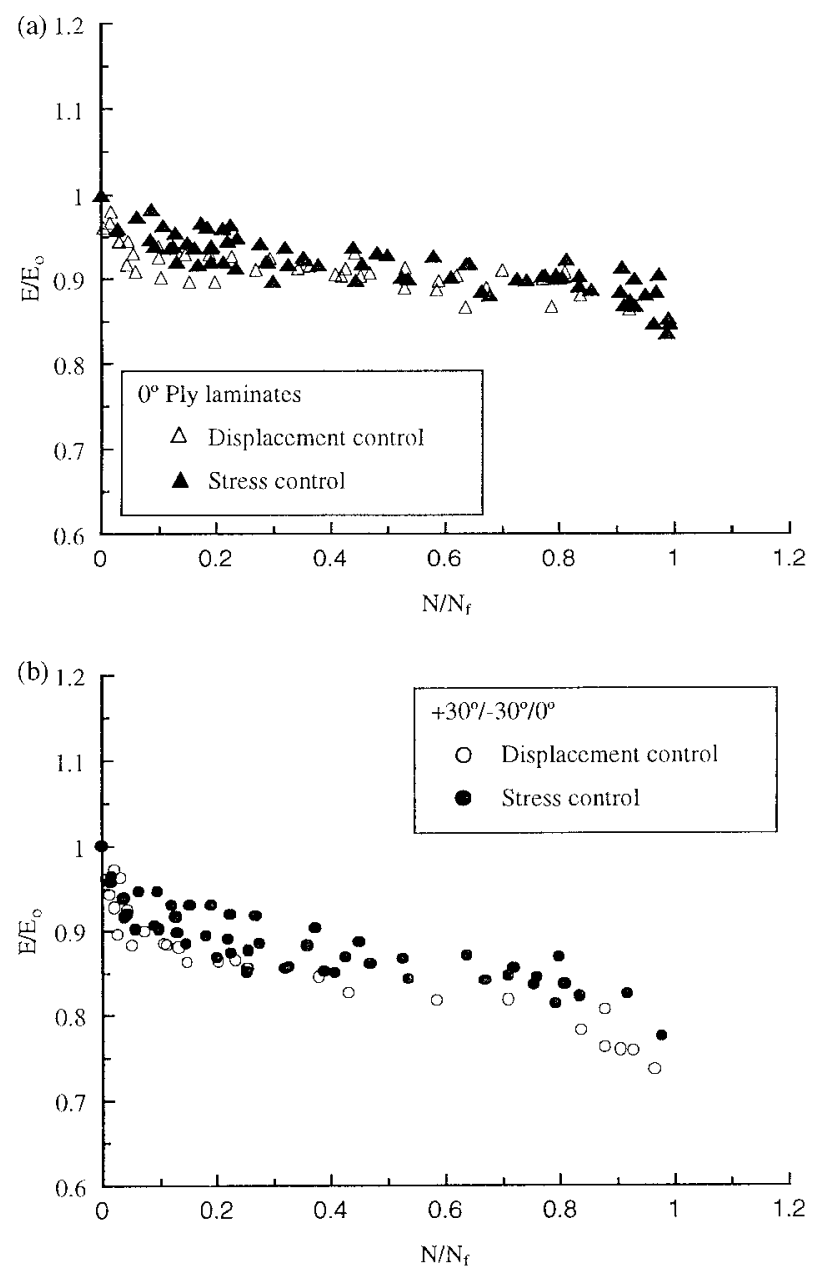

Fig. 4. $E / E_{0}$ plotted against the normalised number of cycles $N / N_{\mathrm{f}}$. (a) $0^{\circ}$; (b) $+30^{\circ} /-30^{\circ} / 0^{\circ}$. 
fatigue life a more pronounced decreasing of the stiffness was observed in the displacement control than in stress control tests. The most important cause to this difference must be the stress release of observed in the
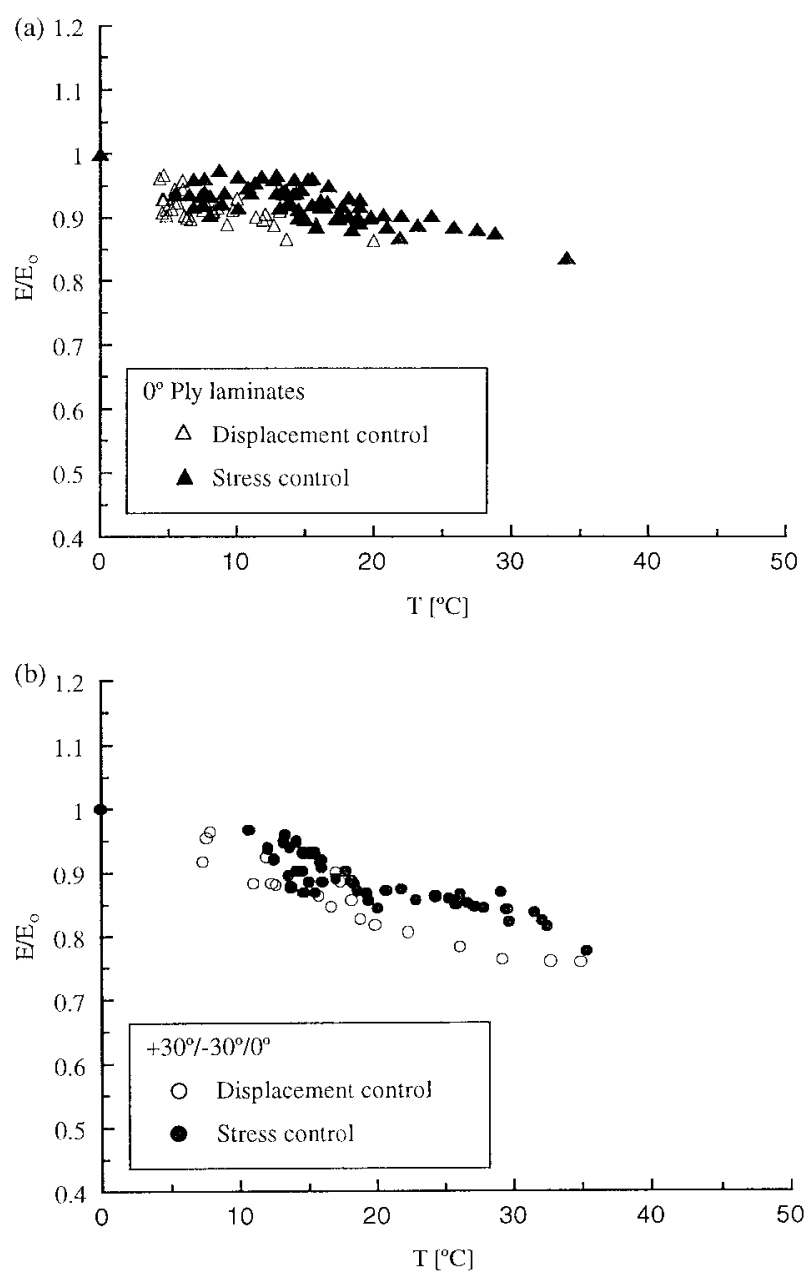

Fig. 5. $E / E_{0}$ plotted against the rise of surface temperature $\Delta T$. (a) $0^{\circ}$; (b) $+30^{\circ} /-30^{\circ} / 0^{\circ}$.

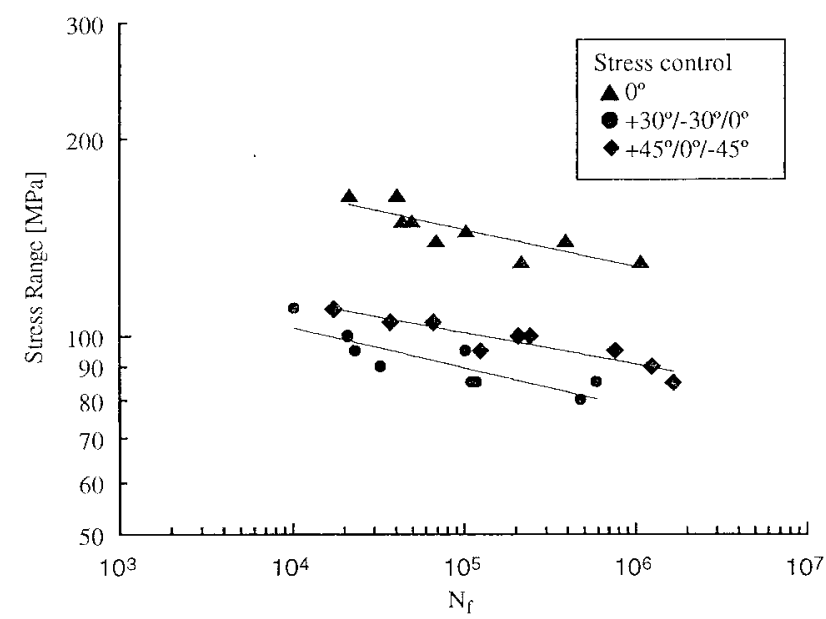

Fig. 6. Influence of lay-up geometry on the S-N curves. Stress controlled tests. material during this period. Tests carried out by the authors show that this stress release at room temperature is very significant during the first $10 \mathrm{~min}$ after load application. Such behaviour can help explain the sudden drop of stiffness observed in the first stage of fatigue. After this first period the results obtained for both test conditions are similar. Other parameters such as the increases in temperature and internal delaminations contribute to the stiffness modulus decreases.

Fig. 5(a) and (b) show plots of loss of stiffness $E / E_{0}$ versus the rise in temperature $\Delta T$ in the $0^{\circ}$ and

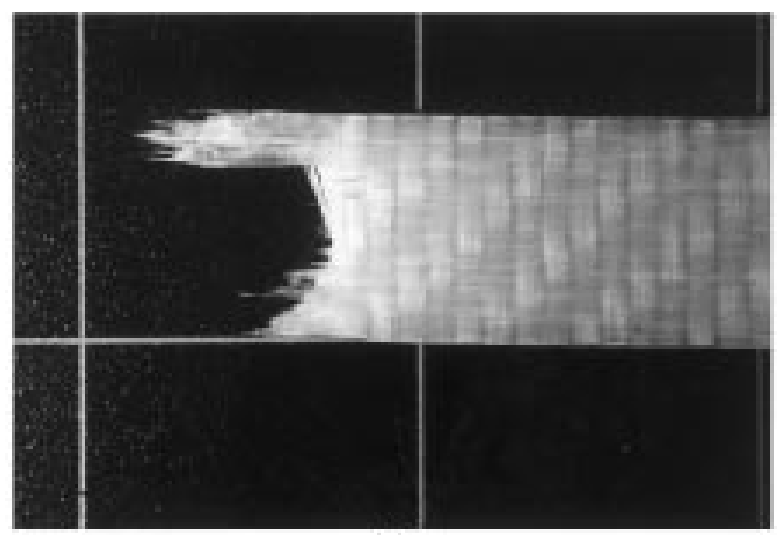

(a)

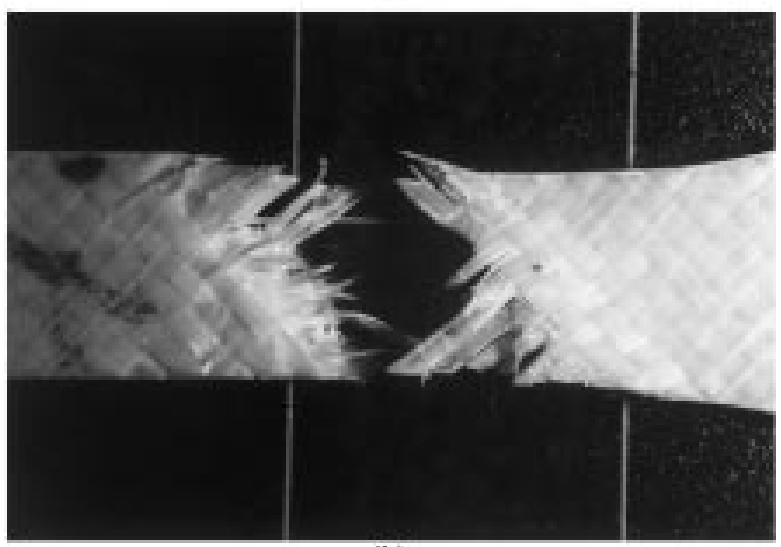

(b)

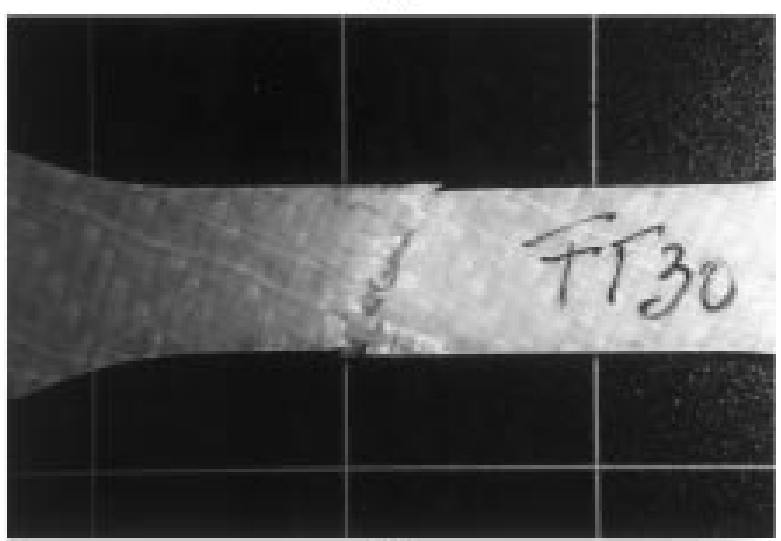

(c)

Fig. 7. Fatigue test fracture specimens. (a) $0^{\circ}$; (b) $+45^{\circ} / 0^{\circ} /-45^{\circ}$; (c) $+30^{\circ} /-30^{\circ} / 0^{\circ}$. 

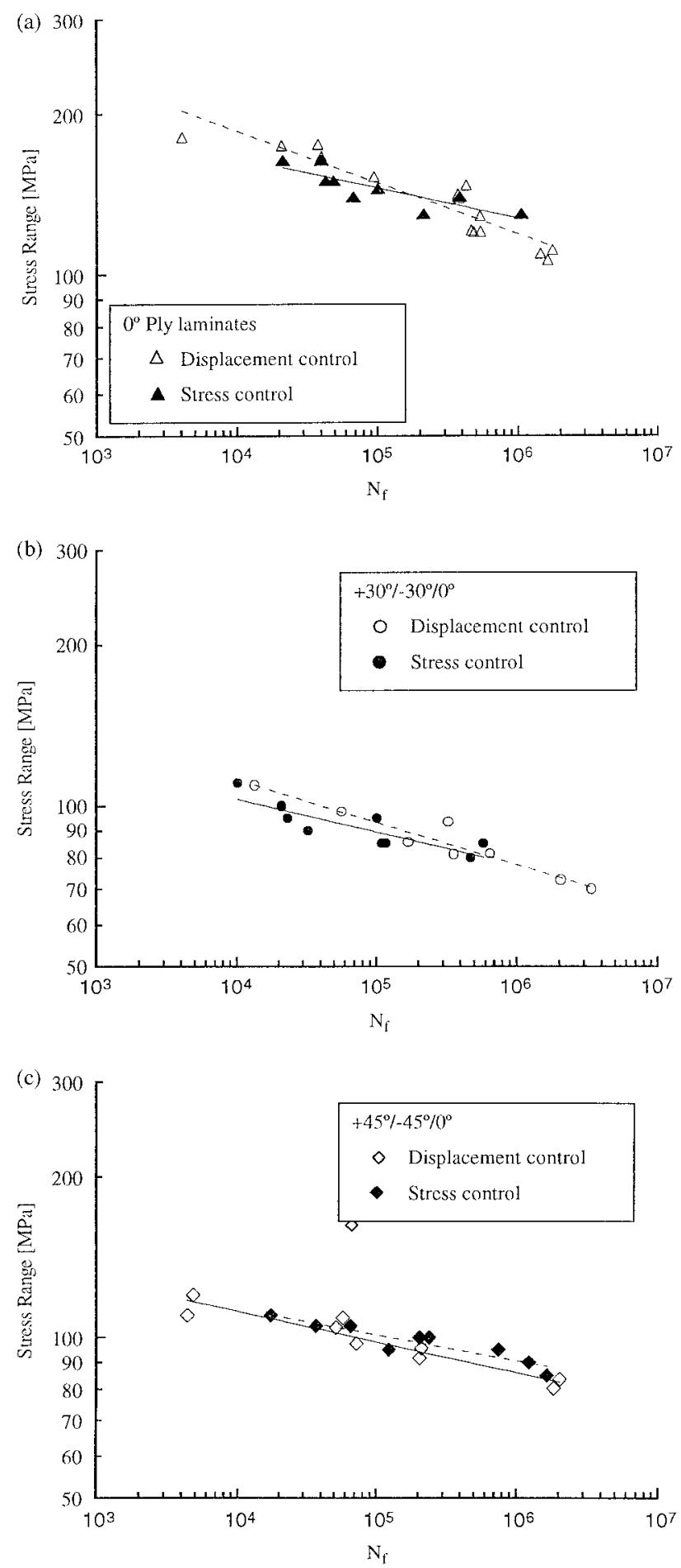

Fig. 8. Influence of loading fatigue mode on the $\mathrm{S}-\mathrm{N}$ curves. (a) $0^{\circ}$; (b) $+30^{\circ} /-30^{\circ} / 0^{\circ}$; (c) $+45^{\circ} / 0^{\circ} /-45^{\circ}$.

$+30^{\circ} /-30^{\circ} / 0^{\circ}$ laminates, respectively. For both laminates and both test conditions a nearly linear decrease of stiffness with the temperature was observed during the second stage. In the first fatigue stage the experimental points do not coincide with the linear fitted curve. The most important cause of this difference must be the stress release observed in the first stage.
The results of the fatigue tests were plotted in terms of stress range versus the number of cycles to failure. Fig. 6 plots the fatigue results obtained under controlled stress mode. The analysis of this figure shows that the fatigue strength of $0^{\circ}$ laminates (where the fibers direction is always the same as the load) is much higher (1.51.8 times) than the other two laminates. This effect is related to the change of failure mechanism. In $+45^{\circ} / 0^{\circ} /$ $-45^{\circ}$ and $+30^{\circ} /-30^{\circ} / 0^{\circ}$ laminates the predominant fatigue mechanism is the debonding between the fibers and matrix caused by normal stresses. The fatigue strength obtained in $+30^{\circ} /-30^{\circ} / 0^{\circ}$ laminates is $10-15 \%$ lower than in $+45^{\circ} / 0^{\circ} /-45$ laminates which is a consequence of the higher normal stress component in the fibers with a $30^{\circ}$ of inclination. The failure is observed in inclined planes along the fiber direction. In $0^{\circ}$ laminate the normal stress is predominantly absorbed by longitudinal fibers and the failure is in transverse planes. Fig. 7 shows the failure modes observed in fatigue tests for the three laminates. The fracture aspect of fatigue failure is very similar to that observed in static failure (Fig. 2). The fatigue strength for $+45^{\circ} / 0^{\circ} /-45^{\circ}$ and $+30^{\circ} /-30^{\circ} / 0^{\circ}$ laminates is similar for low fatigue lives and only a little higher in $+45^{\circ} / 0^{\circ} /-45^{\circ}$ for longer lives.

The fatigue strength obtained in stress controlled and displacement controlled tests is compared in Fig. 8(a), (b) and (c), for $0^{\circ},+30^{\circ} /-30^{\circ} / 0^{\circ}$ and $+45^{\circ} / 0^{\circ} /-45^{\circ}$ laminates, respectively. In these figures the stress range against the number of cycles to failure is plotted. For the displacement control tests the stress range was calculated for the first fatigue cycle. Only a small tendency to increase in fatigue life is observed in the case of displacement controlled tests. In spite of the stress release expected in the displacement controlled mode, and the decrease in stress range caused by the loss of stiffness, the increase in fatigue strength is very small (less than $5 \%)$.

\section{Conclusions}

Similar damage mechanisms are observed in stress controlled tests and strain controlled tests both in $0^{\circ}$ and in multi-angle $+45^{\circ} / 0^{\circ} /-45^{\circ}$ and $+30^{\circ} /-30^{\circ} / 0^{\circ}$ laminates.

Only a small tendency to increase in the fatigue strength (less than 5\%) is observed in all three laminates in displacement controlled mode despite the expected stress release and the decrease of stress range caused by the loss of stiffness during the test.

The fatigue strength is strongly influenced by the layer design. $0^{\circ}$ laminate results have values $1.5-1.8$ times higher than $+45^{\circ} / 0^{\circ} /-45^{\circ}$ and $+30^{\circ} /-30^{\circ} / 0^{\circ}$ laminates which exhibit similar fatigue strengths (although $+30^{\circ} /$ $-30^{\circ} / 0^{\circ}$ is $10-15 \%$ lower than the $+45^{\circ} / 0^{\circ} /-45$ case). 
The loss of stiffness $\left(E / E_{0}\right)$ starts early in the fatigue process life. A sudden drop of $E / E_{0}$ (about $5 \%$ ) is observed during the first $5 \%$ of the fatigue life and thereafter only a small stable decrease is observed until close to failure.

The temperature rise on the surface of the specimens reaches a maximum value at failure. The temperature rises are similar for all laminates and only a small tendency to reach higher values is observed in the case of stress controlled tests. The maximum values are dependent on the stress range and for all tests are in the range of $25-75^{\circ} \mathrm{C}$. A linear relationship is observed between the loss of stiffness $\left(E / E_{0}\right)$ and the temperature rise in second fatigue life period (which was more than $80 \%$ of fatigue life) for all the laminates. A small deviation is observed in the first fatigue life period, especially in strain controlled tests, probably caused by stress release phenomena.

\section{References}

[1] Hou M, Lin Ye, Mai Y. Advances in processing of continuous fibre reinforced composites with thermoplastic matrix. Plastics, Rubber and Composite Processing and Applications 1995;23:279-93.

[2] Harper RC, Pugh JH. Thermoforming of thermoplastic matrix composites. In: Lee SM, editor. International encyclopedia of composites, vol. 5. New York: VCH Publishers, Inc., 1991. p. 496-530.

[3] Ferreira JAM, Costa JDM, Richardson MOW. Fatigue behaviour of a glass fibre reinforced polypropylene composite. Proc. 11th European Conference on Fracture, Poitiers, France, 1996. p. 1653-58.

[4] Ferreira JAM, Costa JDM, Richardson MOW. Effect of notch and test conditions on the fatigue of a glass-fibre-reinforced polypropylene composite. Compos Sci Technol 1997;57:124348.

[5] Pink E, Campbell JD. Deformation characteristics of reinforced epoxy resins, part 1 , the mechanical properties. J Mat Sci 1974;9:658-64.

[6] Sims GD, Gladman DG. Effect of test conditions on the fatigue strength of a glass-fabric laminate: part A-Frequency. Plast and Rubber: Mater and Appl 1978; 41-8.

[7] Sims GD, Gladman DG. Effect of test conditions on the fatigue strength of a glass-fabric laminate: part B - specimen condition. Plast and Rubber: Mater and Appl 1980;8:122-8.

[8] Wen-Fang Wu, Lee LJ, Choi ST. A study of fatigue damage and fatigue life of composite laminates. $\mathbf{J}$ Compos Mater 1996;30(1):123-37.

[9] Spearing M, Beaumont PWR. The fatigue mechanics of composite materials, I: Experimental measurement of damage and postfatigue properties. Compos Sci Technol 1992;44:159-68.

[10] Hahn HT, Kim RY. Fatigue behaviour of composite laminate. J Compos Mater 1976;10:156-80.

[11] Joseph E, Perreux D. Fatigue behaviour of glass-fibre/epoxymatrix filament-wound pipes: tension loading tests and results. Compos Sci Technol 1994;52:469-80.

[12] Echtermeyer AT, Engh B, Buene L. Lifetime and Young's modulus changes of glass/phenolic and glass/polyester composites under fatigue. Composites 1995;26(1):10-16.

[13] Czigany T, Karger-Kocsis J. Determination of the damage zone size in textile fabric reinforced polypropylene composites by locating the acoustic emission. Polym and Polym Compos 1993;1(5):329-39.

[14] Wysgoski MG, Novak GE. Fatigue fracture of long fiber reinforced Nylon 66. Polym Compos 1995;16(1):38-51.

[15] Curtis PT. A review of the fatigue of composite materials. Royal Aircraft Establishment, Technical Report 87031, 1987.

[16] Harris B, Reiter H, Adam T, Dickson RF, Fernando G. Fatigue behaviour of carbon fibre reinforced plastics. Composites 1990;21(3):232-42.

[17] Rotem A, Nelson HG. Fatigue behaviour of graphite-epoxy laminates at elevated temperatures. Fatigue of fibrous composite materials, ASTM STP 723, 1981. p. 152-73. 